\title{
Stroke - TIA Patient's Profile: A Wide Analysis of 157 Cases
}

\author{
Enrico Affonso Barletta ${ }^{1 *}$, Mariana Almeida Vidal'2, Maycon Melo Lopes ${ }^{2}$ and Luis Belini ${ }^{3}$ \\ ${ }^{1}$ Medicine student from Pontifical Catholic University of Campinas, Brazil \\ ${ }^{2}$ Neurology resident on Hospital Puc-Campinas, Brazil \\ ${ }^{3}$ Faculty of Medical Sciences, State University of Campinas vascular neurology postgraduate, Brazil
}

*Corresponding author: Enrico Affonso Barletta, Medicine student from Pontifical Catholic University of Campinas, São Paulo, Brazil, Email: enrico.barletta333@gmail.com.

Received Date: May 20, 2019

Published Date: May 24, 2019

\section{Abstract}

Background: Stroke is one of the main causes of death in the world and it still being the disease that most leaves sequels. So, understanding the profile of the patient who suffers a neurological ischemic event is crucial for all healthcare professionals, specially neurologists and neurosurgeons.

Methods: Observational, descriptive and analytical article, where patients were blindly analyzed. Summaries of hospitalization from patients who suffered an ischemic stroke or a transient ischemic attack were analyzed.

Results: 157 patients were analyzed. The average age was 66,3 years old. $61 \%$ were man and 39\% women. Most important risk factor: Hypertension being in $85 \%$ of them. Most important Toast: Cardioembolic being in $39 \%$ of the cases. Previous stroke in $23 \%$ and TIA occurred in $27 \%$. Injury topography: $83 \%$ anterior circulation; $9 \%$ posterior; $8 \%$ both. Carotid ateromatosis in $42 \%$ of the cases.

Conclusion: Analyzing the patients, many characteristics showed high prevalence. Complementary exams must be requested. Hypertension and diabetes are the most important risk factors. There is a significant TIA rate. Each Toast present particullar risk factors that has major influence on each of them, as well as specific characteristics.

Keywords: Ischemic stroke; Transient ischemic attack; Toast; Epidemiology; Risk factors

\section{Introduction}

There are 5 etiologys or Toasts for an ischemic stroke: Microangiopathy (when small vessels of the brain undergo ischemia); Great Vessels Disease (on wich a great vessel is occludded by an atheroma plaque); Other Causes; Cryptogenic and Cardioembolic (when an embolus originated by the heart goes to a brain vessel, impairing area irrigation) [1-5]. The Toast classification was first described by Adams et al. [5] and ever since the classification was maintained. In this article we used their classification as the foundation for stratifying our patients and to determine the Toasts [5]. Cardioembolic Toast usually represents more serious ischemic strokes, once they are more likely to occlude large vessels, leading to greater areas of brain isquemia. This kind of stroke is caused by cardiac alterations, such as: atrial fibrillation, valve defects, ventricular thrombus, atheroma in the aortic arch, congenital heart defects and myocardial acute infarct [1].
The atherosclerotic injuries of great vessels can be classified into four different clinical scenarios: according to the presence or absence of isquemia symptoms on the extracranial part of carotid artery, presence of atherosclerosis in intracranial arterial segments and atherosclerotic disease in the extracranial part of the vertebral artery [2].

Approximately $30 \%$ of ischemic strokes are considered cryptogenic. However, there are many causes not well known and explored by the physicians, such as: Fabry Disease, CADASIL, Mitochondrial encephalomyopathy, Moyamoya disease, among others [6]. Moyamoya disease is a progressive occlusive vasculopathy that results in stenosis or occlusion of distal internal carotid artery or proximal part of its branches, with later abnormal vascular weave formation $[3,4]$. 
Sistemic arterial hypertension; smoking; etilism; diabetes mellitus; dyslipidemias; chronical atrial fibrillation; cardiopathies and Chagas disease, are classical risk factors that are able to illustrate how different can be the profile and the background of an ischemic stroke patient. The stroke itself is an important risk factor for its recidivism [2,4, 7-11]. TIA is a clinical syndrome characterized for a sudden onset of a neurologic deficit that was originated for any impairment in brain vascular weave and doesn't leave alterations on imaging exams made after the event and usually lasts less than 24 hours. An analysis of cardiovascular system must be done to identify a possible cause of TIA, like atrial fibrillation. Treatments are responsible for a $80 \%$ risk reduction for ischemic stroke occurrence $[12,13]$.

There are many findings related to arteries and heart that influence prevention, treatment, post-hospital conduct, but mainly the identification of stroke's Toast, such as aorta ectasia, left atrial dilatation, left ventricule disfunction, valves diseases and atheroma plaques in carotid artery and its branches, vasculopathies, coagulopathies, patent foramen ovale (PFO), paroxysmal atrialfibrillation (PAF), many times not recognized on a simple EKG, valvular heart-disease, atrial septal aneurysm (ASA) and a left atrial appendage thrombus (LAAT) [14]. LAAT are usually associated with atrial fibrillation and cause systemic thromboembolism complications [15]. ASA has a prevalence of $2 \%$ to $9 \%$ and it's related to PFO in $60 \%$ of the patients [16]. In most cases patients with a PFO don't manifest any symptoms. However, when there is a clot in the blood or just the alteration of the blood flux a stroke is a real concern $[11,17]$.

The occlusion of a specific artery in the encephalon will caracterize the topography of the stroke. These occlusion will cause hypoxia and deterioration of the area irrigated by an artery and the area will not be able to exercise its function anymore, what leads to the symptoms onset. The stroke topography is divided in: anterior circulation, when the occlusion is at a carotid branche or the carotid artery itself or posterior circulation, referring to the vertebral artery and its branches. Some arteries are frequent places of occlusion, what explains the most important symptoms of the illness. The anterior circulation is the most affected, especially the middle brain artery, therefore it must be always focus of investigation in the exams $[9,18,10,19]$.

Stroke is notably more recurrent in elderly people, most cases occur after 60 years old and after each decade the risk of stroke increases significantly $[9,4,10]$. Stroke is one of the main death causes in the world, also in Brazil and still being the disease that most leaves sequels [20].

\section{Methods}

This is an observational and analytical study, that patients were blindly analyzed. The summaries of hospitalization from patients who underwent monitoring in cerebrovascular disease ambulatory and suffered an acute ischemic event (ischemic stroke or transient ischemic attack), in the period from December 2015 to December 2017, at a tertiary Hospital in the city of Campinas (São Paulo) were analyzed. Data about age, risk factors, Toast, TIA occurring, previous strokes, injuries topography and comorbidities were analyzed. To determine the ischemic event mechanism subtype, patients underwent electrocardiography, extracranial and intracranial Doppler ultrasound, transthoracic echocardiography, and at least one brain CT scan. In selected cases, transesophageal echocardiography, 24-hour Holter monitoring, CT angiography or digital angiography were also performed. All the absolute frequencies were calculated among the total cohort and the relative frequencies were obtained by diving the absolute frequencies by the total cohort. The data analyzed were compared with bibliography review. Due to retrospective design of this study, we did not apply for ethics committee approval. We guarantee that no patient were submitted to any process due to this study. We also realized a heterogenous literature review using articles from many different countries, specially from Brazil, once our patients were from this country. We used also data from books and guidelines, once the ischemic stroke is a consecrated disease with some absolute truths. Regarding the articles used we only used articles published in English avaiable in PUBMED between 2000 and 2018. The review part of the article wasn't applied for ethics committee approval due to the retrospective design of this literature review.

\section{Results}

This study includes data of 157 patients, in the abovementioned charactheristics. The avarege age of the analyzed patients was of 66,3 years old. Mens represent $61 \%$ of the patients and women $39 \%$.

\section{Risk factors}

Table 1: Risk factors occurrence in patiens who presented an ischemic event.

\begin{tabular}{|c|c|c|}
\hline Risk Factor & $\begin{array}{l}\text { Absolute } \\
\text { Frequency }\end{array}$ & $\begin{array}{r}\text { Relative } \\
\text { Frequency }\end{array}$ \\
\hline Hypertension & 134 & $85 \%$ \\
\hline Diabetes Mellitus & 50 & $32 \%$ \\
\hline Smoke & 49 & $31,00 \%$ \\
\hline Previous TIA & 42 & $27 \%$ \\
\hline $\begin{array}{l}\text { Previous Ischemic } \\
\text { Stroke }\end{array}$ & 35 & $22 \%$ \\
\hline Ethilism & 34 & $21,00 \%$ \\
\hline Cardiopathy & 31 & $20,00 \%$ \\
\hline Dyslipidemia & 26 & $16,50 \%$ \\
\hline Atrial Fbrillation & 24 & $15,00 \%$ \\
\hline Hypothyroidism & 16 & $10,00 \%$ \\
\hline $\begin{array}{l}\text { Previous Heart } \\
\text { Attack }\end{array}$ & 8 & $5,00 \%$ \\
\hline $\begin{array}{l}\text { Chronic Renal } \\
\text { Insufficiency }\end{array}$ & 7 & $4,00 \%$ \\
\hline Chagas Disease & 3 & $2,00 \%$ \\
\hline $\begin{array}{l}\text { Previous Lung } \\
\text { Complications }\end{array}$ & 3 & $2,00 \%$ \\
\hline Femur Fracture & 2 & $1,00 \%$ \\
\hline
\end{tabular}




\begin{tabular}{|c|c|c|}
\hline HIV+ & 2 & $1,00 \%$ \\
\hline $\begin{array}{c}\text { Moyamoya } \\
\text { Disease }\end{array}$ & 2 & $1 \%$ \\
\hline Drug Addiction & 2 & $1 \%$ \\
\hline Self Medication & 1 & $1 \%$ \\
\hline $\begin{array}{c}\text { Previous } \\
\text { Hemmorhagic Stroke }\end{array}$ & 1 & $1 \%$ \\
\hline $\begin{array}{c}\text { Patent Foramen } \\
\text { Ovale }\end{array}$ & 1 & $1 \%$ \\
\hline Hyperthyroidism & 1 & $1 \%$ \\
\hline
\end{tabular}

ethilism in $21 \%$, cardiopathy in $20 \%$, dislipidemy in $16 \%$ and atrial fibrillation in $15 \%$. The data about the risk factors are avaiable in Table 1.

\section{Toast}

About the stroke etiology or Toast, draws the attention that $39 \%$ of it were cardioembolic, $18 \%$ due to great vessels disease (atherosclerose), 18\% due to microangiopathy, 23\% were cryptogenyc and $2 \%$ were due to other causes $(1 \%$ due to carotid dissection and $1 \%$ due to moyamoya disease). The diabetes mellitus, ex and current smokers, dyslipidemia, atrial fibrillation, previous ischemic stroke, TIA, hypothyroidism and the posterior circulation strokes occurrence, were compared with the stroke's Toast in Table 2. in $32 \%$ of them, smoking in $31 \%$, previous ischemic stroke in $22 \%$,

Table 2: Diabetes mellitus, ex and current smokers, dyslipidemia, atrial fibrillation, previous ischemic stroke, TIA, hypothyroidism and the posterior circulation strokes occurrence compared with stroke's Toast.

\begin{tabular}{|c|c|c|c|c|c|}
\hline & Cardioembolic $(\mathrm{N}=61)$ & Great Vessels $(\mathrm{N}=\mathbf{2 8})$ & $\begin{array}{l}\text { Microangiopathy } \\
\text { (N = 28) }\end{array}$ & $\begin{array}{c}\text { other Causes } \\
(\mathrm{N}=3)\end{array}$ & $\begin{array}{l}\text { Cryptogenic } \\
\qquad(\mathrm{N}=37)\end{array}$ \\
\hline Diabetes Melitus ( $\mathrm{N}=50)$ & 16 & 9 & 13 & 1 & 11 \\
\hline Ex/Current Smokers $(\mathrm{N}=49)$ & 15 & 13 & 7 & 2 & 12 \\
\hline Tia Occurrence $(\mathrm{N}=42)$ & 11 & 4 & 4 & 1 & 22 \\
\hline Previous Ischemic Stroke $(\mathrm{N}=35)$ & 15 & 7 & 4 & 2 & 7 \\
\hline Dyslipidemia $(\mathrm{N}=26)$ & 10 & 4 & 5 & 1 & 6 \\
\hline Atrial Fibrillation $(\mathrm{N}=24)$ & 21 & 0 & 2 & 0 & 1 \\
\hline Hypothyroidism $(\mathrm{N}=16)$ & 4 & 4 & 3 & 0 & 5 \\
\hline $\begin{array}{l}\text { Posterior Circulation } \\
\qquad(\mathrm{N}=26)\end{array}$ & 6 & 6 & 12 & 1 & 1 \\
\hline
\end{tabular}

\section{Topography}

Looking to the ischemic stroke topography $83 \%$ of them had only anterior circulation impairment, $9 \%$ only posterior impairment and 8\% had both.

\section{Complementary exams}

On the complementary exams recurrent comorbidities were found, such as carotid atheromatose in $42 \%$ of the cases, mitral insuficiency in $25 \%$, left ventricule dillatation in $19 \%$, left ventricule hipertrophy in $18 \%$ of them among other findings that can be seen in Table 3.

Table 3: Complementary Exams Findings.

\begin{tabular}{|c|c|c|}
\hline $\begin{array}{c}\text { Recurrent Comorbidities in } \\
\text { Exams }\end{array}$ & $\begin{array}{c}\text { Absolute } \\
\text { Frequency }\end{array}$ & $\begin{array}{c}\text { Relative } \\
\text { Frequency }\end{array}$ \\
\hline Carotid Atheromatosis & 66 & $42,00 \%$ \\
\hline Mitral Insufficiency & 39 & $25,00 \%$ \\
\hline Left Ventricular Dysfunctions & 30 & $19 \%$ \\
\hline Left Ventricular Hypertrophy & 29 & $18,00 \%$ \\
\hline Aortic Insufficiency & 23 & $15 \%$ \\
\hline Atrial Enlargement & 23 & $15,00 \%$ \\
\hline Aortic Ectasia & 21 & $13 \%$ \\
\hline Gyrus and Sulcus Atrophy & 14 & $9,00 \%$ \\
\hline Pulmonary Hypertension & 10 & $6,00 \%$ \\
\hline Intracranial Aneurysms & 8 & $5,00 \%$ \\
\hline Aortic Atheromatosis & 8 & $5,00 \%$ \\
\hline
\end{tabular}

\section{TIA cases}

TIA occurred in $27 \%$ of our patients. $90 \%$ of those patients presented hypertension, 36\% diabetes mellitus, 21\% cardiopathy, $19 \%$ were ex or current smokers, the others risk factors are presented in Table $4.95 \%$ of this population suffered an anterior circulation TIA, $2 \%$ posterior circulation and $2 \%$ commited both circulations. Among the 157 patients analyzed who presented an ischemic event (ischemic stroke or TIA), 2 of them presented Moyamoya Disease, both patients presented a TIA and not an ischemic stroke. This relation is available at Table 5.

Table 4: Risk factors of TIA patients.

\begin{tabular}{|c|c|c|}
\hline \multicolumn{3}{|c|}{ Tia Patients (N = 42) } \\
\hline Risk Factor & Absolute Frequency & Relative Frequency \\
\hline Hypertension & 38 & $90 \%$ \\
\hline Diabetes Mellitus & 15 & $36 \%$ \\
\hline Cardiopathy & 9 & $21 \%$ \\
\hline Smokers & 8 & $19 \%$ \\
\hline Hypothyroidism & 5 & $12 \%$ \\
\hline Dyslipidemia & 5 & $12 \%$ \\
\hline Atrial Fibrillation & 3 & $7 \%$ \\
\hline Moyamoya Disease & 2 & $5 \%$ \\
\hline
\end{tabular}

Table 5: Moyamoya Disease occurrence.

\begin{tabular}{|c|c|}
\hline \multicolumn{2}{|c|}{ Moyamoya Disease Occurrence } \\
\hline Stroke Patients & Tia Patients \\
\hline 0 & 2 \\
\hline
\end{tabular}




\section{Discussion}

\section{Hypertension}

Chaves et al. [21] and Ovbiagele et al. [7] showed that the hypertension is the most important risk factor for ischemic stroke [7,4,21-23]. $40 \%$ to $50 \%$ of the ischemic strokes are caused by hypertension in U.S.A [7]. Boehme et al. [4] reported that the proportion of strokes in the population attributable to hypertension is approximatly 54\%. Yao et al. [22] after analyze 858 patients who suffered an ischemic stroke and 844 health patients matching with the gender and age of ischemic stroke patients in the same period, reported that the incidence of ischemic stroke in hypertensive population was $62.6 \%$. Among the ischemic stroke patients group $69 \%$ of them presented hypertension [22]. Lange et al. [23] after analyzing 359 patients that suffered their first ischemic stroke episode reported that $82,1 \%$ of them had hypertension [23]. In this study $85 \%$ of the selected patients suffer from this illness, being in that way the most important risk factor of our cohort, what corroborates the literature findings.

\section{Atrial fibrillation}

The patients with atrial fibrillation have 5 times more chance to suffer an ischemic stroke [24]. The atrial fibrillation is the cause of $15 \%$ to $20 \%$ of the strokes [25]. In this study $15 \%$ of the patients analyzed have intermittent or permanent atrial fibrillation. In Brazil it can be seen similar examples, where 16,7\% of the the patients that suffered an ischemic stroke present atrial fibrillation [25], corroborating these finds ischemic stroke with cardioembolic Toast was very prevalent in the tertiary hospital evaluated Albert Einstein, as well as in the present study. Lange et al. [23] also reported that between their group of 359 patients $18,3 \%$ of the patients presented atrial fibrillation, besides that $58 \%$ of the 107 patients that suffered an ischemic stroke due to cardio embolism presented atrial fibrillation and $94 \%$ of the patients that presented atrial fibrillation suffered an ischemic stroke due to cardio embolism, demonstrating the importance of this arrhythmia for the stroke development [16]. In the present study $87,5 \%$ of the patients that presented atrial fibrillation suffered an ischemic event due to cardio embolism and $36 \%$ of the patients that suffered a cardioembolic event presented atrial fibrillation. Perera et al. [26] after studying 14 patients who presented an ischemic stroke with a previous history of subclinical atrial fibrillation $57 \%$ of them presented cardioembolic Toast. However among 5 patients who had subclinical atrial fibrillation detected within 30 days before their ischemic stroke episode, $80 \%$ presented a cardioembolic stroke [26]. Those findings speaks in favour of our results.

\section{Diabetes mellitus}

Diabetes mellitus is considered an independent risk factor for the development of ischemic stroke and it can raise 4 times the risk to develop the disease [10]. Boehme et al. [4] reported that diabetes is an independent risk factor for stroke with a 2 -fold increased risk and stroke represent approximately $20 \%$ of deaths in diabetics patients [4]. Among Lange et al. [23] 359 patients group 30,3\% of them presented diabetes. $38,2 \%$ of their patients who presented microangiopathy as their Toast presented diabetes [23]. This study showed that $32 \%$ of the patients analyzed have diabetes. Among our microangiopathy Toast patients $46,4 \%$ presented diabetes. Others significant studies founds that this prevalence can vary from $22 \%$ to $45 \%[8,27]$.

\section{Smoking}

Guzik et al. [8] showed that the smoker patient has a 2-fold increased risk to present an ischemic stroke and it was also observed that the risk is dose dependent [8,4]. Boehme et al [4] also reported that cigarette smoking doubles the risk for ischemic stroke. They also estimate that smoking is reesponsible for approximatly $15 \%$ of all stroke deaths per year. Even secondhand smoke is as an independent risk factor for stroke, once this population present a $30 \%$ increased risk of stroke [4]. Yao et al. [22] reported that in the 858 ischemic stroke patients group 23,1\% of them smoke. Among Lange et al. [23] 359 patients group 26,4\% of them were current smokers when they presented their first ischemic stroke. Besides that $36,7 \%$ of their great vessels disease Toast patients were smokers [23]. In the present study $31 \%$ of the patients presented high rates of smoking. Among the patients who presented great vessels disease as the stroke Toast, $46,4 \%$ of them smoked, showing the importance of smoking for the development of this Toast. Other Toast that presented high rates of smokers was the other causes Toast $(66,6 \%)$, however we only had 3 cases of this Toast so this data doesn't has a significant estatistic value.

\section{TIA occurrence}

TIA occurred in $27 \%$ of our patients. $52,3 \%$ of this population presented cryptogenic Toast and 26,2\% presented as its Toast cardioembolism. $59,4 \%$ of the patients who presented cryptogenic Toast presented a TIA. In the U.S.A the rates varies from $1 \%$ to $6 \%$ and $10 \%$ of patients that presented a TIA will develop an ischemic stroke in the next 90 days [12,7]. Giarola et al. [28] reported that 15 to $30 \%$ of all strokes are preceded by TIA. Ater analyzing 258 they showed that 31 patients presented a previous TIA (12\%) [28]. It's likely that the high rate of TIA occurrence found in the present study is due to the high level of cardioembolic Toast, that is associated to transitory events. However the cryptogenic Toast has a major importance for the TIA etiology, what shows that the TIA occurrence is probably related with many others factors, such as PFO presence as described by Mazzucco et al. [29]. The risk factors rates of TIA patients is very similar compared to all patients who suffered an ischemic event, so the same risk factors for the occurrence of an ischemic stroke is a risk factor for TIA ocurrence. However $100 \%$ of patients who presented Moyamoya Disease had a TIA and not an ischemic stroke, what shows that patients who present this disease has a major risk to develop a TIA. TIA's topography is similar to the total population of this study also, once the anterior circulation is the most affected.

\section{Sex}

About the prevalence of the ischemic stroke according to the sex, we had conflicting data with the literature [8]. Lange et al. [23] for example reported that among their 359 patients $49 \%$ of them 
were woman [23]. Haast et al. [30] also stated the importance of female sex as a risk factor for the stroke incidence, especially in postmenopausal women, once the authors presented a relation between the sex hormones, which plays a role in the vessel dynamics (dilatation and atherosclerotic process). In the present study $61 \%$ of the patients analyzed were man and 39\% were women.

\section{Toast}

About the stroke etiology in this study $18 \%$ of the strokes analyzed presented as its Toast great vessels disease, in the literature it's seen a rate that varies from $14 \%$ to $40 \%[2,10,31]$. Among the 258 patients analyzed by Giarola et al. [28] 16\% of them presented great vessels diseases as its Toast [28]. Between the 359 patients that Lange et al. [23] analyzed $22 \%$ of them presented as the stroke Toast great vessels disease [23]. Even in levels usually not so high, the constancy of this etiology in several countries can be seen. In fact, this Toast is related with high rates of carotid atheromatosis found, which in this study is present in $42 \%$ of the cases, being the most important comorbidity found. Dyslipidemia occurrence is usually related with this Toast. In Lange et al. [23] study only $23,7 \%$ of the patients that suffered an ischemic stroke and presented dyslipidemia had great vessels as the stroke's Toast, but among the patients that suffered a stroke due to great vessels disease $63,2 \%$ of them presented dyslipidemia [23]. In the present study $16,5 \%$ of the patients analyzed presented dyslipidemia. Among those patients only 15,3\% presented great vessels disease as the event Toast and only $14,2 \%$ of the patients total who presented this Toast presented dyslipidemia. Therefore this leads us to think that dyslipidemia isn't more important in great vessels disease Toast, this risk factor impacts and increases the chance of all kind of stroke occurence. We confirmed that once the prevalece of dyslipidemia is very similar in cardioembolic, great vessels, microangiopathy, other causes and cryptogenic Toasts, they were respectively $16,4 \% ; 14,2 \% ; 17,8 \% ; 33,3 \%$ and $16,2 \%$.

In the present study $18 \%$ of the ischemic events were caused by microangiopathy. Several of the main studies shows a porcentage ranging from $15 \%$ to $30 \%$ for ischemic strokes with microangiophatic Toast [10,31]. Among Giarola et al. [28] patients $11 \%$ of them presented microangiopathy as its Toast [28]. Lange et al. [23] showed a prevalence of $19 \%$ for microangiophatic Toast among the 359 patients studied [23].

In the present study $39 \%$ of the ischemic events analyzed have $39 \%$ of cardioembolic Toast. In the literature it's found a rate ranging from $15 \%$ to $30 \%[1,31]$.

Giarola et al. [28] reported a prevalence of $42 \%$ for cardioembolic Toast among their patients [28]. Lange et al. [23] showed a prevalence of $30 \%$ of cardioembolic Toast in their patients [23]. Therefore, it was found in this study a higher rate, that we credit to a broad realization of the exam 24 hours cardiac Holter, what increase the sensibility to detect intermittent atrial fibrillation when compared to the electrocardiogram. Nevertheless, the practice of the electrocardiogram realized in two periods during the hospitalization increase the chance of detection of that atrial arrhythmia. The literature describes rates from up to $40 \%$ of ischemic stroke with cryptogenic Toast occurrence [3,31,32], what goes against our findings, because this study has a cryptogenic Toast rate of $23 \%$. We also credit this rate to a broad realization of 24 hours cardiac Holter. Giarola et al. [28] reported a 25\% rate of cryptogenic Toast among their 258 patients [28]. Lange et al. [23] showed a prevalence of $23 \%$ for cryptogenic Toast [23]. Those findings shows that a wide search for the ischemic event etiology result in a wide capacity to determine its Toast. Agreeing with our findings, some researchs shows the importance of ministrate anticoagulants in patients with cryptogenic stroke, that present some abnormalities, like: LAAT, PAF or a PFO [14,15]. Mazzucco et al. [29] after studying 264 patients who presented cryptogenic events and underwent a bubble-TCD reported a significant association between right to left shunt (PFO) and cryptogenic events in the older population [29].

\section{Topography}

In the present study $83 \%$ of the patients suffered an ischemic event with anterior circulation impairment and 17\% of them involved the posterior circulation, corroborating the literature findings, like Schulz et al. [19], who described that $20 \%$ of the strokes are located at posterior circulation $[10,19]$. Among the posterior circulation patients $23 \%$ of them presented cardioembolic Toast, $23 \%$ great vessels disease, $46 \%$ microangiopathy, $4 \%$ other causes and $4 \%$ other causes. Among the patients that presented an ischemic event due to microangiopathy $42,8 \%$ of them were at the posterior circulation and among the patients who had great vessels disease $21,4 \%$ of them were at the posterior circulation. Therefore we conclude the importance of microangiopathy for the posterior circulation ischemic events. The great vessels disease is the second most important Toast for those events.

\section{Conclusion}

After analyzing the 157 patients, selected to the study, many characteristics showed high prevalence. The patient that suffers from an ischemic event often have some cardiovascular alterations, such as mitral insuficiency or aorta ectasia, a lot of times they present carotid atheromatosis despite the Toast. However each Toast present particular risk factors that has major influence on each of them, as well as specific characteristics. Atrial fibrillation and other heart diseases are some findings that are present in many cases and influence the stroke's etiology, even when the stroke is cryptogenic, cardiovascular diseases must be analyzed, once the use of anticoagulation may be an alternative in some cases. Therefore investigational exams must be widely requested and analyzed for the practice of a better secondary prophylaxis. Hypertension, diabetes, smoking, ethilism and dyslipidemia are the most important risk factors for ischemic stroke and TIA patients. Transitory symptoms that do not cause changes in the exams can't be despised, because there is a significant rate of TIA cases and many times those preced the occurrence of an ischemic stroke or those cases can disclose a vasculopathy, such as Moyamoya Disease. Treatments like the carotid revascularization, anticoagulation, antiplatelet agents, statins, antihypertensive drugs and lifestyle 
changes are responsible for a reduction of $80 \%$ in the occurrence of an ischemic event, so we highlight that a specialized monitoring in a vascular neurology center decrease drastically the recurrence and the occurrence of an ischemic event as it's observed over this study.

\section{Acknowledgement}

None.

\section{Conflict of Interest}

No conflict of interest.

\section{References}

1. American Stroke Association (2017) Transient Isquemic Attack. Available at http://www.strokeassociation.org/STROKEORG/ AboutStroke/TypesofStroke/TIA/Transient-Ischemic-Attack-TIA_ UCM_492003_SubHomePage.jsp.

2. Oh Young Bang, Mi Ji Lee, Sookyung Ryoo, Suk Jae Kim, Ji Won Kim (2015) Patent Foramen Ovale and Stroke-Current Status. J Stroke 17(3): 229-237.

3. Bazzano LA, He J, Ogden LG, Loria CM, Vupputuri S, et al. (2002) Fruit and vegetable intake and risk of cardiovascular disease in US adults: the first National Health and Nutrition Examination Survey Epidemiologic Follow-up Study. The American journal of clinical nutritional 76: 93-99.

4. Boehme AK, Esenwa C, Elkind MS (2017) Stroke Risk Factors, Genetics, and Prevention. Circulation research 120(3): 472-495.

5. Centers of disease control and prevention. Atrial Fibrillation Fact Sheet. Available at: https://www.cdc.gov/dhdsp/data_statistics/fact_sheets/ fs_atrial_fibrillation.htm.

6. Chaves, Márcia L F (2000) Acidente vascular encefálico: conceituação e fatores de risco. Revista brasileira de hipertensão: 372-382.

7. Banerjee C, Moon YP, Paik MC, Rundek T, Mora-McLaughlin C, et al. (2012) Duration of diabetes and risk of ischemic stroke -The Northern Manhattan Study. Stroke 43: 1212-1217.

8. John W Cole (2017) Large Artery Atherosclerotic Oclusive Disease. CONTINUUM: Lifelong Learning in Neurology. Cerebrovascular Disease 23(1): 133-157.

9. Coutts SB (2017) Diagnosis and Management of Transient ischemic attack. CONTINUUM: Lifelong Learning in Neurology 23(1): 82-92.

10. Finsterer J (2010) Management of cryptogenic stroke. Acta Neurol Belg 110(2): 135-147.

11. Giarola BF, Leyden J, Castle S, Jannes J, Anderson C, et al. (2018) Transient Ischaemic Attack Rarely Precedes Stroke in a Cohort with Low Proportions of Large Artery Atherosclerosis: A Population-Based Study. Cerebrovascular diseases extra 8(2): 101-105.

12. Guzik A, Bushnell C (2017) Stroke epidemiology and risk factor management. CONTINUUM: Lifelong Learning in Neurology: 23(1): 1539.

13. Huang JF (2017) Prevention and Management of Poststroke Complications. CONTINUUM: Lifelong Learning in Neurology: 23(1): 93110.

14. Jichici Draga (2017) Anterior Circulation Stroke. Available at http:// emedicine.medscape.com/article/1159900-overview.

15. Koyama T, Otsuka Y, Kawahara M, Imoto Y, Nakamura K, et al. (2017) A left atrial appendage thrombus that developed during prophylactic low- dose dabigatran treatment resolved after switching to apixaban. Clin Case Rep 5(5): 711-713.

16. Lange MC, Ribas G, Scavasine V, Ducci RD, Mendes DC, et al. (2018) Stroke recurrence in the different subtypes of ischemic stroke. The importance of the intracranial disease. Arq Neuropsiquiatr 76(10): 649-653.

17. Li Y, Fitzgibbons TP, McManus DD, Goddeau RP, Silver B (2019) Left Ventricular Ejection Fraction and Clinically Defined Heart Failure to Predict 90-Day Functional Outcome After Ischemic Stroke. J Stroke Cerebrovasc Dis 28(2): 371-380.

18. Lorga Filho Adalberto, Lorga Adalberto Menezes, Lopes Alberto Nicodemus G, Paola Ângelo AV de, Costa Álvaro Barros da, et al. (2003) Diretriz de fibrilação atrial. Arquivo Brasileiro de Cardiologia 81: 2-24.

19. Majersik, Jennifer Juhl (2017) Inherited and Uncommon Causes of Stroke. CONTINUUM: Lifelong Learning in Neurology 23(1): 211-237.

20. Mazzucco S, Li L, Binney L, Rothwell PM; Oxford Vascular Study Phenotyped Cohort (2018) Prevalence of patent foramen ovale in cryptogenic transient ischaemic attack and non-disabling stroke at older ages: a population-based study, systematic review, and meta-analysis. Lancet Neurol 17(7): 609-617.

21. O'Carroll, Cumara B, Barrett, Kevin M (2007) Cardioembolic Stroke. CONTINUUM: Lifelong Learning in Neurology 23(1): 111-132.

22. Ovbiagele B, Nguyen-Huynh MN (2011) Stroke Epidemiology: Advancing Our Understanding of Disease Mechanism and Therapy. Neurotherapeutics 8(3): 319-329.

23. Perera KS, Sharma M, Connolly SJ, Wang J, Gold MR, et al. (2018) Stroke type and severity in patients with subclinical atrial fibrillation: An analysis from the Asymptomatic Atrial Fibrillation and Stroke Evaluation in Pacemaker Patients and the Atrial Fibrillation Reduction Atrial Pacing Trial (ASSERT). Am Heart J 201: 160-163.

24. Rivera, Ivan Romero Mendonça, Maria Alayde (2013) Aneurisma do Septo Interatrial em Adultos: Diagnóstico e Classificação. Rev bras ecocardiogr imagem cardiovasc 26(1): 33-37.

25. Roland, Lewis P (2000) Mazzoni, Pietro. Merritt's Neurology. 10 $0^{\text {th }}$ (edn.), Roland, Lewis P, pp. 1- 528.

26. Scheffel (2004) Rafael Selbach Prevalência de complicações micro e macrovasculares e de seus fatores de risco em paciente com diabetes melito do tipo $2 \mathrm{em}$ atendimento ambulatorial. Revista da Associação Médica Brasileira 50(3): 263-267.

27. Schulz UG, Fischer U (2017) Posterior circulation cerebrovascular syndromes: diagnosis and management. J Neurol Neurosurg Psychiatry 88(1): 45-53.

28. Silva Gisele S, Miranda, Renata CAN, Massaud Rodrigo M (2015) Acidente Vascular Cerebral - Prevenção, tratamento agudo e reabilitação. Rio de Janeiro. Atheneu 1-336.

29. Southerland AM (2017) Clinical Evaluation of the Patient with Acute Stroke. CONTINUUM: Lifelong Learning in Neurology 23(1): 40-61.

30. Yao S, Li H, Liu K, Leng G, Yu J (2018) Study on the application of classification tree model in screening the risk factors of ischemic stroke. In: Zhonghua Wei Zhong Bing Ji Jiu Yi Xue 30(10): 973-977.

31. Adams HP Jr, Bendixen BH, Kappelle LJ, Biller J, Love BB (1993) Classification of subtype of acute ischemic stroke. Definitions for use in a multicenter clinical trial. TOAST. Trial of Org 10172 in Acute Stroke Treatment. Stroke 24(1): 35-41.

32. Haast RA, Gustafson DR, Kiliaan AJ (2012) Sex differences in stroke. J Cereb Blood Flow Metab 32(12): 2100-2107. 